\title{
Behaviorism in Online Teacher Training
}

\author{
Danielle E. Kaplan \\ California School of Education, Alliant International University, San Francisco, United States of America \\ Email: dkaplan@alliant.edu
}

How to cite this paper: Kaplan, D. E. (2018). Behaviorism in Online Teacher Training. Psychology, 9, 570-577.

https://doi.org/10.4236/psych.2018.94035

Received: February 10, 2018

Accepted: April 8, 2018

Published: April 11, 2018

Copyright $\odot 2018$ by author and Scientific Research Publishing Inc. This work is licensed under the Creative Commons Attribution International License (CC BY 4.0).

http://creativecommons.org/licenses/by/4.0/

\begin{abstract}
This research involves the study of Behaviorism in Online Teacher Education. Behaviorism theories were included in an online course in cognition and critical thinking in education as foundational psychological frameworks to apply to educational practice. Participants applied theoretical frameworks in instruction and learning design in the form of analyses, lessons and projects. Analyses were group discussions over the readings and their application to practice. Lesson Designs were full-length lessons for inclusion with applications of theory. Project Designs were group projects incorporating theory into an educational resource. Analyses, lessons and projects were analyzed for understanding and application of theory.
\end{abstract}

\section{Keywords}

Psychology, Education, Instruction, Teacher Training, Critical Thinking, Behaviorism

\section{Introduction}

The California School of Education at Alliant International University has included a course in Critical Thinking for Teaching and Learning in a sequence of courses designed to prepare current and future educators to develop thinkers. A previous paper (Kaplan, 2017) describes the course. Included in the course were overarching frameworks guiding design, core relevant content, poignant and significant assignments, and meaningful communication. Course skill and learning outcomes include critiquing psychological theories in teaching and learning and applying theories in education.

Behaviorist theories, including those of Pavlov (Liddell, 1936; Clarke, 2004), (Thorndike, 1927; Waters, 1934), Watson (Gewirtz, 2001), and Skinner (1963), have informed many disciplines on methods of influencing behavior, including providing valuable insights for teaching, training, and learning in education 
(Tomic, 1993; Bitterman, 2006). The theories describe how behavior can be conditioned through varying techniques shaping the environment of a human. Classical conditioning formalizes treatments in which stimulus is provided to induce a particular response. Operant conditioning defines conditions where reward and consequences are issued to reinforce behavior. Theories about conditioning offer wonderful suggestions for how to design instruction to support learning and are important in the training of teachers.

The overarching objective of this research is to continue foundational understanding and application of Behaviorist theory in the training of teachers. A further objective is to develop the online instructional technologies to accomplish this goal. This paper describes the participants, instruments, analysis and results of applying Behaviorist theory in teacher training.

\section{Design}

\subsection{Participants}

Study participants included Alliant International University California School of Education Credential and Master of Education students enrolled in Critical Thinking in Teaching and Learning over the course of several Terms over two years. Twenty-one of sixty students volunteered to include their work in the study, five male and 16 female. The participant body is made up of teachers and teachers in training of multiple ethnicities on intern and student teaching tracks in special education, single subject in varying subject areas, multiple subject credentials, and Teaching English as a Second Language (TESOL). Those who agreed to participate were made up of two Multiple Subject candidates, fourteen Single Subject candidates including two in Math, two in English, three in Physical Education, two in Science, two in Language, two Educational Specialists, four undeclared, and one TESOL candidate. Selection was determined by required participation in the course and volunteering for the study. The volunteers were representative of the course participants and teacher candidates in the University.

\subsection{Instruments}

Study instruments were embedded into the Critical Thinking in Teaching and Learning online course Behaviorism Module. Participants were presented with Behaviorism resources and assignments comprised of analyses, lesson designs, and projects. Participants completed activities individually and in groups during the course of the week of the module and submitted their assignments online. Understanding and application of theory were measured group analyses, lesson designs and group project designs received through online submissions in digital word or web format. Group analyses involved reflection on the readings, their classroom, and final project. Lesson designs required selection of a topic to teach based upon State Standards with a design incorporating the reading. Group project designs were culminating group or individual work incorporating the 
reading into projects to improve critical thinking.

\subsection{Analysis}

Student constructions were analyzed for theory understanding and referencing and application of theory in education. Theory discussions and analysis noted whether they acknowledged and noted theory and what they found relevant in the theory. Lesson analysis involved accounting for and describing referencing to theory and application of theory in lesson design. Projects were analyzed for theory referencing and application in project design.

\section{Behaviorism Module}

Module 2 is a unit on behaviorist theories of psychology in critical thinking and education. The components of all Modules and Module 2 are described by Kaplan in a previous paper (2017). Module 2 is described below. The goal of the module is to provide an overview of behaviorist theories. Learning objectives include analyzing principles of behaviorism and determining how to effectively apply the principles of behaviorism in lesson plan and project design.

The module is made up of readings, forums, and assignments. Readings include Cherry (2016), Cooper (2013), Standridge (2002), Culatta (2015), Danley, James, Mims, \& Simms (nd), Baum (2004), and Peel (2005). Each reading presents foundational theories in behaviorism including Watson, Thorndike, Skinner, and Pavlov. Assignments include brainstorming in project groups over how to incorporate behaviorist theories into project design, researching technology for project, selecting insights from behaviorist theorists and incorporating into lesson designed in previous assignments, and providing meaningful feedback to classmates' lesson designs.

\section{Results}

\subsection{Theory Analysis and Application}

All of the participants referenced Thorndike, Skinner, Pavlov and/or Watson in reflecting upon various forms of conditioning in shaping behavior and in applying this to teaching strategies upon reading their theories. Many students mentioned Pavlov and classical conditioning, discussing stimulus for a particular response in conditioning behavior. For example, one participant recommended stimulating critical thinking with fun activity. Another participant considered how to stimulate behavior of standing up for community rights. Another participant designed stimuli to change shy behavior via social stimulus in online networking encouraging interpersonal interaction. Several participants noted emulation and modeling as stimulus. One participant suggested using music as stimulus for though, activity change or attention. One participant suggested changing stimulus depending on learning style.

Many students mentioned Skinner and reinforcement, discussing methods of providing consequences and positive reinforcement to encourage or discourage 
behavior. For example, one student considered classroom interaction design in reinforcing behavior. Many students considered how to change behavior through positive reward and praise. One participant recommended training teachers and parents to implement rule setting, reinforcement, consequence, and praise. Another participant noted planned input, reinforcement, practice, feedback, motivation, and reward were all useful recommendations from the theories. One participant added feedback designs to their exit tickets to provide reinforcement. One participant recommended positive reinforcement for relieving math anxiety. Several participants recommended rewards for desired behavior such as candy, raffle tickets, point tracking, and free time. Many participants mentioned repetition of response as important.

Table 1 shows a number count for whether Behaviorist theories were referenced and applied in Analyses out of twenty-one participants in twenty groups. Some participants applied one or both sets of theories.

Table 1. Reference and application of theory in analyses.

\begin{tabular}{ccc}
\hline \multirow{2}{*}{\begin{tabular}{c} 
Reference and Application of \begin{tabular}{c} 
Theory in Analyses \\
\cline { 2 - 3 }
\end{tabular} \\
\cline { 2 - 3 }
\end{tabular}} & Stimulus/Response & Theory \\
\hline & 12 & 13 \\
\hline
\end{tabular}

\subsection{Applications in Lesson Designs}

All of the participants discussed conditioning in applying conditioning techniques in their lesson designs. One participant discussed and applied conditioning by creating a welcoming environment, rules and expectations set with a culture of encouragement and consistent encouragement in understanding math and angles.

Several participants mentioned and applied Skinner's principles of controlled and planned input, reinforcement, practice, feedback, motivation and reward, for example in a fun engaging project based learning unit in history on an adventure travel. Several participants mentioned behavioral analysis as fundamental in teaching.

Several participants mentioned stimulus response theory. One participant, discussing Watson, advocated the importance of a stimulating environment in encouraging learning, noting more stimulation will lead to more engagement. Several students recommended creating a nurturing environment removing negative stimuli to stimulate learning and study. Another participant, discussing Pavlov, recommended an online quiz as a stimulus to create excitement. Another participant, considering Pavlov's use of sound in stimulating salivation, considered using sound in stimulating student behavior, such as in gaining attention or another participant in incorporating feedback signals to indicate when to transition behavior or activity.

Many participants advocated and applied positive reinforcement techniques in their lesson design, such as reward and praise. One participant designed a 
lesson with trial and error activity in identifying incorrect bar graphs, using positive reinforcement with stimulus reward opportunity for extra credit. Several participants designed in extra credit, for example in a lesson in art and political communication. One participant noted the importance of acknowledgement of accomplishment. One participant recommended having students who are doing well provide positive support to struggling students, as well as using candy as positive reinforcement. One participant designed student conditioning to raise their hand for important questions, but not for no reason, receiving praise for raising the hand appropriately. One lesson incorporated positive reinforcement in encouraging more outgoing behavior in social networking. One participant recommended immediate feedback after modeling behavior. Another added feedback layers to their exit tickets. Several participants noted students work for what brings positive feeling, and designed systems to create positive feeling such as token systems. Several participants suggested rewarding with candy. One participant designed methods of modifying unhealthy eating habits by presenting healthier ones and rewarding them. Few participants recommended or mentioned negative reinforcement techniques. One participant referenced Standridge in recommending ignoring undesired behavior as opposed to issuing negative consequences.

Table 2 shows a number count for whether Behaviorist theories were referenced and applied in Lesson Designs out of twenty-one participants. Some participants applied one or both sets of theories.

Table 2. Reference and application of theory in lesson designs.

\begin{tabular}{ccc}
\hline \multirow{2}{*}{$\begin{array}{c}\text { Reference and Application of } \\
\text { Theory in Lesson Designs }\end{array}$} & \multicolumn{2}{c}{ Theory } \\
\cline { 2 - 3 } & Stimulus/Response & Reinforcement/Consequences \\
\hline 17 & 19 \\
\hline
\end{tabular}

\subsection{Applications in Project Designs}

All but two projects referenced Behaviorist theories presented as a component of the foundation of their project design. Several projects advocated creating a positive environment as stimulus for positive development of good behavior. Several participants recommended analyzing student behavior and dynamics to better design how students positively or negatively influence each other, referencing Watson's suggestion to analyze the organism in the environment. Skinner's principles controlled and planned input, reinforcement, practice, feedback, motivation and reward were recommended in several projects, including a travel adventure language program trying to eliminate fear of communicating and encouraging communication speaking with others and initiating conversations through social reinforcement and a history adventure program. One participant mentioned stimulus conditioning with whistle sounds to gather attention and indicate activity task rotation in Physical Education. Another participant lured students with competitive game play in an online quiz between lectures as en- 
couragement. An alternative assessment program designed changes to student stimulus based upon student learning style for desired responses.

Most participant projects incorporated negative and positive reinforcement into the project design, with predominantly positive reinforcement employed in design through praise and reward. One participant noted importance of the Teacher as the guide and reinforcer, particularly with Autistic children. One project integrated negative and positive feedback in a new Algebra Learning and Teaching Cycle program. Another project rewarded when students respond correctly in an athletic emergency training program. A Homework pass was given to those who complete their work in first assignment in reading and analyzing texts in another project. Another project designed conditioning through reinforcement and punishment and stimuli for motivation in physical education. A healthy kids nutrition site incorporated positive rewards for positive choices like healthy eating and exercise for obesity and diabetes. Positive and negative feedback and reward in an online forum were designed into a program for learning and developing critical thinking.

Table 3 shows a number count for whether Behaviorist theories were referenced and applied in Project Designs out of twenty-one participants in twenty groups. Some participants applied one or both sets of theories.

Table 3. Reference and application of theory in project designs.

\begin{tabular}{ccc}
\hline \multirow{2}{*}{$\begin{array}{c}\text { Reference and Application of } \\
\text { Theory in Project Designs }\end{array}$} & Stimulus/Response & Theory \\
\cline { 2 - 3 } & 13 & 14 \\
\hline
\end{tabular}

\section{Conclusion}

Behaviorism Theories of Psychology are of benefit to support instruction and learning. This course was successful in inspiring teacher candidates to analyze and apply Behaviorist theory to instruction. Upon reading theories in behaviorism, teacher education candidates referenced and applied theories in strategic ways to develop behavior involved in study and learning in discussions, lesson designs, and final projects. Strategies from the theories, which arose as beneficial to teaching, included creating a positive environment with positive stimuli and reducing negative stimuli, analyzing the environment and social dynamics for positive and negative stimuli, rewarding desired behavior, discouraging undesired behavior with negative consequences or being ignored, praising desired behavior, and repetition. The results of this study suggest Behaviorist theories should be included in the teaching of teachers in developing their repertoire of knowledge and skills needed to shape student development.

Results show participants were able to understand and reference the theories and it is highly likely this is a result of the reading resources and experiencing the discussions in the course. However, there was no pretest to test prior understanding to experiencing the course readings and module, or proof their understanding 
didn't come from other sources outside of the course. Therefore, a causal claim about the effect of instruction cannot be made from this study. A future study might pretest knowledge and compare groups who have experienced the resources and groups who have not to make a causal claim about instruction. While all participants referenced and applied theory, not all participants referenced and applied all theories. The assignments could be redesigned to require this or improve inducing everyone's referencing of all components of the theory in another way. Future research might include a larger sample from future participants.

\section{References}

Baum, W. M. (2004). Part I: What Is Behaviorism? In Understanding Behaviorism: Behavior, Culture, and Evolution (2nd Ed.). Indianapolis, IN: Wiley-Blackwell.

http://www.blackwellpublishing.com/content/bpl_images/content_store/sample_chapt er/9781405112611/baum_sample\%20chapter_understanding\%20behaviourism.pdf

Bitterman, M. E. (2006). Classical Conditioning since Pavlov. Review of General Psychology, 10, 365-376. https://doi.org/10.1037/1089-2680.10.4.365

Cherry, K. (2016). The Origins of Psychology: A Brief History of Psychology through the Years. Verywell, an About.com brand.

https://www.verywell.com/the-origins-of-psychology-2795245

Clarke, R. E. (2004). The Classical Origins of Pavlov's Conditioning. Integrative Physiological \& Behavioral Science, 39, 279-294. https://doi.org/10.1007/BF02734167

Cooper, S. (2013). Behaviorism Theory Overview. Life Circles Inc.

Culatta, R. (2015). Behaviorist Learning Theory. Innovative Learning Theory com. http://www.innovativelearning.com/teaching/behaviorism.html

Danley, B., James, N., Mims, C., \& Simma, A. (nd). Behaviorism Theory: And Its Relation to Instructional Design. Mercer University.

http://faculty.mercer.edu/codone_s/tco363/2014/behaviorism.pdf

Gewirtz, J. L. (2001). J. B. Watson's Approach to Learning: Why Pavlov? Why Not Thorndike? Behavioral Development Bulletin, 10, 23-25. https://doi.org/10.1037/h0100478

Kaplan, D. E. (2017). Online Teacher Training of Cognition and Learning in Education. Psychology, 8, 373-386. https://doi.org/10.4236/psych.2017.83023

Liddell, H. S. (1936). Pavlov's Contribution to Psychology. Psychological Bulletin, 33, 583-590. https://doi.org/10.1037/h0057515

Peel, D. (2005). The Significance of Behavioural Learning Theory to the Development of Effective Coaching Practice. International Journal of Evidence Based Coaching and Mentoring, 3, 18-28. http://ijebcm.brookes.ac.uk/documents/vol03issue1-paper-02.pdf

Skinner, B. F. (1963). Operant Behavior. American Psychologist, 18, 503-515. https://doi.org/10.1037/h0045185

Standridge, M. (2002). Behaviorism. In M. Orey (Ed.), Emerging Perspectives on Learning, Teaching, and Technology.

Thorndike, E. L. (1927). The Law of Effect. The American Journal of Psychology, 39, 212-222. https://doi.org/10.2307/1415413

Tomic, W. (1993). Behaviorism and Cognitivism in Education. Psychology: A Journal of Human Behavior, 30, 38-46. 
Waters, R. H. (1934). The Law of Effect as a Principle of Learning. Psychological Bulletin, 31, 408-425. https://doi.org/10.1037/h0073664 